\title{
Similarity and differences in morphology and mechanisms of the foF 2 and TEC disturbances during the geomagnetic storms on 26-30 September 2011
}

\author{
Maxim V. Klimenko ${ }^{1,2}$, Vladimir V. Klimenko ${ }^{1}$, Irina E. Zakharenkova ${ }^{1}$, Konstantin G. Ratovsky ${ }^{3}$, \\ Nina A. Korenkova ${ }^{1}$, Yury V. Yasyukevich ${ }^{3}$, Anna A. Mylnikova ${ }^{3}$, and Iurii V. Cherniak ${ }^{4}$ \\ ${ }^{1}$ West Department of Pushkov IZMIRAN, RAS, Kaliningrad, Russia \\ ${ }^{2}$ Immanuel Kant Baltic Federal University, Kaliningrad, Russia \\ ${ }^{3}$ Institute of Solar-Terrestrial Physics, SB RAS, Irkutsk, Russia \\ ${ }^{4}$ University of Warmia and Mazury, Olsztyn, Poland \\ Correspondence to: Maxim V. Klimenko (maksim.klimenko@mail.ru)
}

Received: 29 July 2016 - Revised: 18 June 2017 - Accepted: 26 June 2017 - Published: 9 August 2017

\begin{abstract}
This study presents an analysis of the groundbased observations and model simulations of ionospheric electron density disturbances at three longitudinal sectors (eastern European, Siberian and American) during geomagnetic storms that occurred on 26-30 September 2011. We use the Global Self-consistent Model of the Thermosphere, Ionosphere and Protonosphere (GSM TIP) to reveal the main mechanisms influencing the storm-time behavior of the total electron content (TEC) and the ionospheric F2 peak critical frequency ( $f o \mathrm{~F} 2)$ during different phases of geomagnetic storms. During the storm's main phase the long-lasting positive disturbances in TEC and foF 2 at sunlit mid-latitudes are mainly explained by the storm-time equatorward neutral wind. The effects of eastward electric field can only explain the positive ionospheric storm in the first few hours of the initial storm phase. During the main phase the ionosphere was more changeable than the plasmasphere. The positive disturbances in the electron content at the plasmaspheric heights (800-20000 km) at high latitudes can appear simultaneously with the negative disturbances in TEC and $f_{o} \mathrm{~F} 2$. The daytime positive disturbances in foF 2 and TEC occurred at middle and low latitudes and at the Equator due to $n(\mathrm{O}) / n\left(\mathrm{~N}_{2}\right)$ enhancement during later stage of the main phase and during the recovery phase of the geomagnetic storm. The plasma tube diffusional depletion and negative disturbances in electron and neutral temperature were the main formation mechanisms of the simultaneous formation of the positive distur-
\end{abstract}

bances in $f_{o} \mathrm{~F} 2$ and negative disturbances in TEC at low latitudes during the storm's recovery phase.

Keywords. Ionosphere (ionospheric disturbances; modelling and forecasting; general or miscellaneous)

\section{Introduction}

The way the ionosphere $\mathrm{F}$ region and total electron content (TEC) respond to geomagnetic storms is one of the most essential and unresolved issues in ionospheric physics and has been widely discussed for decades (Mayr and Volland, 1973; Mayr et al., 1978; Prölss, 1995, 2013; Schunk and Sojka, 1996; Buonsanto, 1999; Schunk and Nagy, 2000; Mendillo, 2006). Theoretical studies have been performed using different numerical models of the ionosphere (Pirog et al., 2006; Balan et al., 2009, 2010; Huba et al., 2000; Pavlov and Pavlova, 2011), as well as more complex models of the Earth's upper atmosphere (Sojka et al., 1994; Namgaladze et al., 2000; Fuller-Rowell et al., 2007; Lei et al., 2008; Lu et al., 2008; Pawlowski et al., 2008; Klimenko et al., 2011ac). These studies have greatly increased our understanding of the formation mechanisms of the ionospheric response to geomagnetic storms. Despite undeniable progress in this research direction, there are still many open questions and contradictions, in particular understanding the mechanisms of the positive ionospheric storm formation in the ionospheric $F$ region and total electron content (TEC). During geomag- 
netic storms, there occurs heating of the thermosphere caused by the strengthening of the high-latitude ionospheric electric fields, currents and auroral particle precipitation. This heating leads to the appearance of additional equatorward neutral wind (Mayr et al., 1978). The equatorward neutral wind moves the plasma upward (due to ion-neutral collisions) along the inclined geomagnetic field lines at low and mid-latitudes into the regions with lower chemical loss rates in ion-molecular reactions; this results in an increase in Fregion electron density (Rishbeth and Garriott, 1969; Mayr et al., 1978; Prölss, 1995). In the vicinity of the Equatorial Ionization Anomaly (EIA), the equatorward neutral wind reduces the downward plasma diffusion along the geomagnetic field lines that also produces positive disturbances in the electron density at the vicinity of the geomagnetic equator. As shown by Rishbeth and Garriott (1969) the occurrence of the additional eastward electric field leads to the additional electromagnetic drift with poleward direction in the plane of the geomagnetic meridian and to the upward plasma transport into the region of lesser chemical loss rate, which leads to the positive effects in the ionospheric F-region electron density at low and middle latitudes. Daytime eastward electric field in the vicinity of the geomagnetic equator produces an increase in the electron density at the EIA crests, their shift to higher latitudes, and the deepening of the EIA trough at the geomagnetic equator. Mannucci et al. (2005) demonstrated that an increase in TEC at middle latitudes is accompanied by the EIA intensification, and suggested that this is due to the vertical and horizontal transport of ionospheric plasma. Heelis et al. (2009) concluded that an equatorward expansion of the high-latitude convection pattern resulted in the TEC enhancements at middle and low latitudes.

Using model simulation results Namgaladze et al. (2000), Lu et al. (2008), Balan et al. (2009, 2010) and Klimenko et al. (2011c, 2015a) confirmed the Mayr et al. (1978) theory, reporting that the equatorward neutral wind is required to produce positive ionospheric storms at middle and low latitudes during daytime hours. Considerable debate on mechanisms of the positive ionospheric storms (Rishbeth et al., 2010; Heelis et al., 2013; Tsurutani et al., 2013) has not ended with a single point of view on this issue. According to Tsurutani et al. (2013), in order to explain the positive ionospheric storms, it is necessary to have the combined action of prompt penetration magnetospheric convection electric fields to low latitudes, equatorward expansion of the affected area of magnetospheric convection to lower latitudes and neutral wind disturbances. It is obvious that such a formulation requires further clarification. It is necessary to determine the spatial and temporal boundaries of the discussed mechanisms' impact on the formation of positive ionospheric storms, as well as other mechanisms such as neutral composition change and ionosphere-plasmasphere interaction.

Only few studies were published on another important issue - correlations between storm-time disturbances of the F2 layer peak critical frequency, $f o F 2$ (which is related to the F2 layer peak electron density, $N_{\mathrm{m}} F 2 \mathrm{~m}^{-3}=1.24 \times 10^{10}$ $\left.(f o \mathrm{~F} 2 \mathrm{MHz})^{2}\right)$, and TEC (e.g., Maruyama et al., 2004; Wang et al., 2013; Liu et al., 2016). TEC and $f_{o} \mathrm{~F} 2$ are the most important and useful parameters in the ionospheric variability studies and various applications. Nowadays the dense networks of the Global Positioning System (GPS) receivers and ionosondes allow the simultaneous coverage of TEC and $f_{o} \mathrm{~F} 2$ values at different sites. One of the main limitations of the GPS technique is that the value of GPS TEC has an integral character, and it is difficult to determine precisely the ionospheric contribution to the GPS TEC based on the GPS measurements only. Ground-based ionosondes provide observations of the electron density for altitudes below the F2 layer peak. Generally, it is assumed that TEC variability can be represented by $f o \mathrm{~F} 2\left(N_{\mathrm{m}} F 2\right)$ variability. This assumption is based on the arguments that TEC and foF 2 are highly correlated (Liu et al., 1996) and the electron density at plasmasphere is several orders of magnitude lower than the F-region electron density (Gallagher et al., 2000). However, recent studies demonstrate that (1) $N_{\mathrm{m}} F 2$ and TEC behavior can be significantly different during a geomagnetic storm especially at a recovery phase (Cherniak et al., 2014), (2) the contribution of the topside ionosphere and plasmasphere to TEC results in a shift to earlier hours and weakening of the Midlatitude Summer Evening Anomaly in TEC as compared to one in $N_{\mathrm{m}} F 2$ (Klimenko et al., 2015b), and (3) sometimes the regions above the $\mathrm{F} 2$ layer peak height provide the largest contribution to TEC (Afraimovich et al., 2011; Klimenko et al., 2015c). This effect is even more pronounced during nighttime at the solar activity minimum, where the plasmaspheric contribution to TEC can exceed the ionospheric one (Lunt et al., 1999a, b; Cherniak et al., 2012; Klimenko et al., 2015c). In fact, the TEC variability depends on the lower and topside ionosphere as well as the plasmasphere (Balan et al., 2002; Gulyaeva and Gallagher, 2007; Yizengaw et al., 2008; Cherniak et al., 2012; Lee et al., 2013; Zakharenkova et al., 2013; Klimenko et al., 2015b, c; Lei et al., 2015). Previous studies have demonstrated both the positive correlation between TEC and $f o \mathrm{~F} 2$ at high and middle latitudes during many storm events and no evident correlation between TEC and $f o \mathrm{~F} 2$ at low and middle latitudes during some storms (Maruyama et al., 2004; Liu et al., 2012). Recent studies (Astafyeva et al., 2015; Lei et al., 2015; Liu et al. 2015) demonstrate that the topside and bottomside ionosphere can react with opposite sign to a geomagnetic storm, which complicates the understanding of how these parts can finally contribute to the storm-time TEC variation. Several important issues regarding the relationship between $f o \mathrm{~F} 2$ and TEC disturbances are still unresolved: (1) what is the global relationship between $f o \mathrm{~F} 2$ and TEC response to geomagnetic storms, and (2) how does this relationship vary with time, storm phase, longitude and latitude? It is important to note that only a limited number of first-principle models allow for this problem to be investigated, because the majority of the developed models have an upper boundary much lower than 
(a)

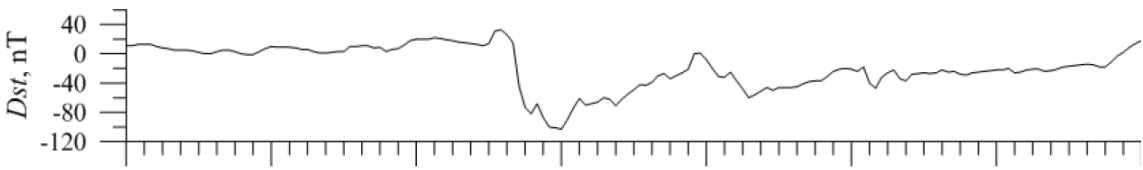

(b)

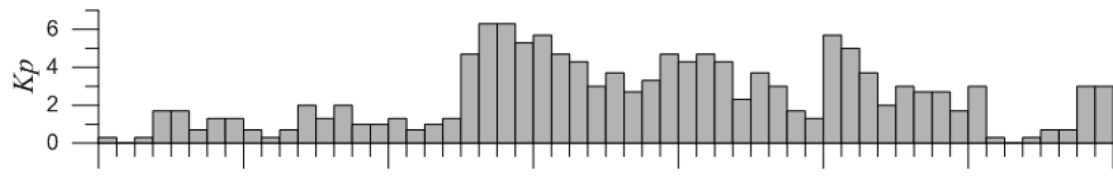

(c)
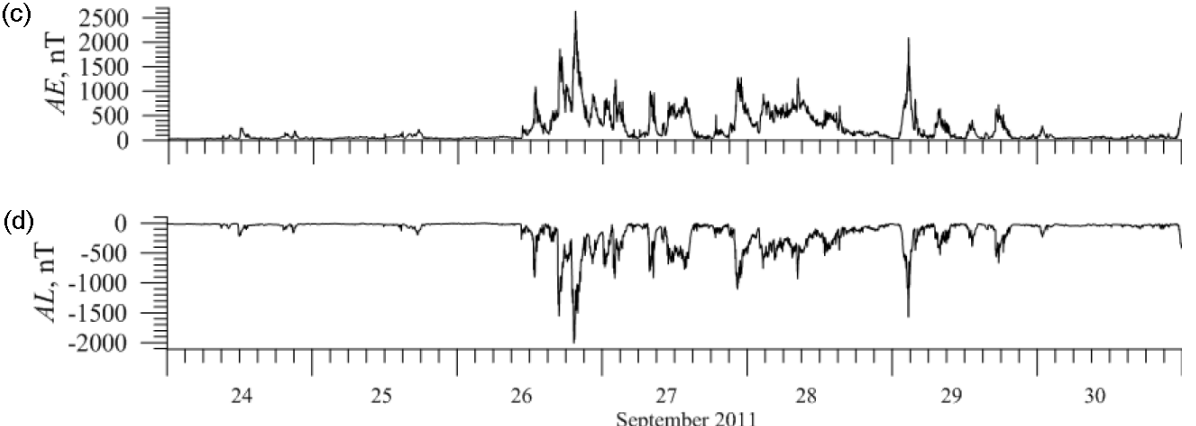

Figure 1. Behavior of the Dst, Kp, AE and AL indices of geomagnetic activity during disturbed periods from 24 to 30 September 2011.

the GPS satellite orbits (Roble and Ridley, 1994; Jin et al., 2012).

The thermospheric heating at high latitudes during geomagnetic storms increases the scale height of all neutral species including molecular nitrogen, which in turn leads to a decrease in the $n(\mathrm{O}) / n\left(\mathrm{~N}_{2}\right)$ ratio at heights of the ionospheric F region (Mayr et al., 1978). As atomic oxygen is the primary source of ionization at the F-region heights, and molecular nitrogen is the primary source of recombination, the change of the $n(\mathrm{O}) / n\left(\mathrm{~N}_{2}\right)$ ratio controls the daytime electron density. The daytime reduction of this ratio leads to the negative disturbances in electron density at the ionospheric F-region heights (Rishbeth and Garriott, 1969). However, at night, when the main ionization source (solar radiation) is almost absent, molecular nitrogen plays a dominant role in the electron density control by neutral composition changes. The additional equatorward wind formed by the same thermospheric heating also leads to the transport of atomic oxygen toward the middle and equatorial latitudes with velocity much greater than the transport velocity of the molecular thermospheric species (Mayr et al., 1978). This brings us to the following question: what happens in the thermosphere-ionosphere system during 1-2 days after the action of the storm-time high-latitudinal thermospheric heating source? The ionospheric F-region disturbances during the recovery phase of geomagnetic storms are one of the most unexamined issues on the topic of the ionosphere's response to a geomagnetic storm. This issue has only been broadly discussed in recent years (Balan et al., 2013; Suvorova et al., 2013; Klimenko et al., 2015a). The problem is very important in terms of understanding the interrelated processes in the up- per atmosphere, and it is the key problem for the selection of background values to study the ionospheric disturbance effects of different origin. Therefore, it is necessary to carry out a study of the temporal development of spatial distribution of the ionospheric disturbances during the recovery phase of geomagnetic storms and to clarify the impact of the neutral composition changes and ionosphere-plasmasphere connections to the formation of such ionospheric effects. Here, by making use of both observation and model simulation results, we present a comprehensive study of the ionospheric disturbances in the ionospheric F2 peak and TEC during the main and recovery phases of the geomagnetic storms on 26 30 September 2011.

\section{Geomagnetic storm description}

We analyze the ionospheric response to geomagnetic storms occurred on 26-29 September 2011. Figure 1 illustrates the geomagnetic conditions in late September 2011. The intense geomagnetic storm started with a storm sudden commencement (SSC) at 12:35 UT on 26 September 2011 and reached a minimum Dst of $-100 \mathrm{nT}$ at 24:00 UT on 26 September. A rapid decrease in the Dst index occurred during the main storm phase. Further, a moderate geomagnetic storm occurred with SSC at 21:00 UT on 27 September, while the Dst index reached its minimum of $-60 \mathrm{nT}$ at 08:00 UT on 28 September 2011. The Kp and auroral electrojet (AE) indices showed high values for the whole period of 26 29 September 2011. The AE index reached the maximum value of $2000 \mathrm{nT}$ at $\sim$ 19:30 UT on 26 September and Kp 
did not exceed 6 . This event occurred during the ascending phase of the 24th solar cycle with the F10.7 index, varying from 133.4 up to 148.2. Ionospheric response to this geomagnetic storm event was studied by Hairston et al. (2013), Wang et al. (2013), Kotova et al. (2015), Klimenko et al. (2015a), Solomentsev et al. (2015), and Chen et al. (2016).

\section{Observation data}

We analyze the database constructed of the F2 peak critical frequency $(f o \mathrm{~F} 2)$ and the total electron content values (TEC) derived from the Irkutsk $\left(52.3^{\circ} \mathrm{N}, 104.3^{\circ} \mathrm{E}\right)$ and Kaliningrad $\left(54.6^{\circ} \mathrm{N}, 20.0^{\circ} \mathrm{E}\right)$ ionosondes and co-located GPS receivers. The $f o \mathrm{~F} 2$ values were derived from the manually scaled ionograms using the interactive ionogram scaling software SAO Explorer (Khmyrov et al., 2008) in the case of the Irkutsk ionosonde and the PARUS software (Karpenko and Manaenkova, 1996) for the Kaliningrad ionosonde. The $f o \mathrm{~F} 2$ sampling rate was $15 \mathrm{~min}$ for Irkutsk and $1 \mathrm{~h}$ for Kaliningrad. As a reference of the ionospheric parameters over these ionospheric stations we calculated their median values and interquartile range from all geomagnetically quiet days in the range of \pm 13 days with respect to 26 September 2011 .

The diurnal GPS TEC variations over Irkutsk and Kaliningrad were derived from the raw observations provided by the ground-based GPS stations. Also, in the analysis we involved the GPS TEC observations derived from the IGS global ionospheric maps (GIMs) generated on the basis of the worldwide network of ground-based GNSS receivers (e.g., Hernández-Pajares et al., 1999). GIMs are produced and released independently by several IGS centers (e.g., CODE, ESAG, JPLG, EMRG) with different set of stations and algorithms. Here we used the IGSG final product, which is a combined map generated from all GIMs. The spatial range of GIMs in standard IONEX format (ftp://cddis.gsfc.nasa.gov/ pub/gps/products/ionex/) is from 0 to $360^{\circ}$ in longitude and from -87.5 to $87.5^{\circ}$ in latitude; dimensions of the elementary GIM cell are $5^{\circ}$ in longitude and $2.5^{\circ}$ in latitude. We extract TEC data from GIMs and generate the daily files of TEC latitudinal profiles for three specific geographic longitudes $\left(105,15^{\circ} \mathrm{E}\right.$ and $\left.75^{\circ} \mathrm{W}\right)$ that represent the closest longitudes to Irkutsk (the east Siberian sector) and Kaliningrad (the European sector) and the American longitudinal sector. Here, we chose the TEC variation for the previous quiet day of 24 September 2011 as a reference value. Comparison of the TEC variability during the quiet day of 24 September 2011 and disturbed period of 26-30 September 2011 revealed the TEC disturbance evolution with time over the selected longitudes.

\section{Brief description of GSM TIP and statement of the problem}

The Global Self-consistent Model of the Thermosphere, Ionosphere, and Protonosphere (GSM TIP) (Namgaladze et al., 1988; Korenkov et al., 1998) was developed in the WD IZMIRAN (West Department of Pushkov Institute of Terrestrial Magnetism, Ionosphere, and Radio Wave Propagation, Russian Academy of Sciences). This model calculates timedependent global three-dimensional distributions of temperature, composition and velocity vector of neutral gas; density, temperature, and velocity vectors of atomic and molecular ions and electrons; and two-dimensional distribution of electric potential, both of a dynamo and magnetospheric origin. All model equations are solved by the finite-difference method. The Earth's magnetic field is approximated by the tilted dipole. Thus, the discrepancy between the geographical and geomagnetic axes is taken into account. Klimenko et al. $(2006,2007)$ have recently modified the calculation of electric fields. This modification to the GSM TIP model allow us to investigate more correctly the equatorial ionosphere (Klimenko et al., 2011b, c, 2012). The modified GSM TIP model has been already used to study the ionospheric behavior during geomagnetic storms from 2000 till 2011 (Klimenko et al., 2011a-c, 2015a; Klimenko and Klimenko, 2012), and we obtained the following most important results: (1) we explained the F3 layer formation mechanism and multi-layer structure in the equatorial $\mathrm{F}$ region during geomagnetic storms; (2) we correctly revealed the ionospheric effects of the disturbance dynamo electric field, the prompt penetration magnetospheric convection electric field to midand low latitudes and overshielding effects; and (3) we investigated the formation mechanisms of the positive and negative ionospheric storms. The comparison of the model results of various ionospheric parameters with observations in high, mid- and low-latitude ionosphere presented in these articles revealed satisfactory qualitative and sometimes quantitative agreement.

To calculate the cross-polar cap potential difference $\Delta \Phi$ we set $\Delta \Phi$ at geomagnetic latitudes $\pm 75^{\circ}$ according to (Feshchenko and Maltsev, 2003) we used the expression $\Delta \Phi=38+0.089 \times \mathrm{AE}(\mathrm{kV})$. The changes of the polar cap sizes were not taken into account. Using experimental results of (Snekvik et al., 2007; Cheng et al., 2008), we have constructed the empirical dependences of the R2 FAC (region 2 field-aligned current) amplitudes from the $\mathrm{AE}$ index of geomagnetic activity: $j_{2}\left(\mathrm{~A} \mathrm{~m}^{-2}\right)=3 \times 10^{-8}+$ $1.2 \times 10^{-10} \times \mathrm{AE}$. We have also included the $30 \mathrm{~min}$ time delay of the R2 FAC variations with respect to the variations in cross-polar cap potential difference (Kikuchi et al., 2008). In addition, according to Sojka et al. (1994) we varied the position of the R2 FAC maximum depending on changes of a cross-polar cap potential difference: $\pm 65^{\circ}$ for $\Delta \Phi \leq 40 \mathrm{kV} ; \pm 60^{\circ}$ for $40 \mathrm{kV}<\Delta \Phi \leq 50 \mathrm{kV} ; \pm 55^{\circ}$ for $50 \mathrm{kV}<\Delta \Phi \leq 88.5 \mathrm{kV} ; \pm 50^{\circ}$ for $88.5 \mathrm{kV}<\Delta \Phi \leq 127 \mathrm{kV}$; 
$\pm 45^{\circ}$ for $127 \mathrm{kV}<\Delta \Phi<165.4 \mathrm{kV} ; \quad \pm 40^{\circ}$ for $165.4 \mathrm{kV}<\Delta \Phi \leq 200 \mathrm{kV} ; \pm 35^{\circ}$ for $\Delta \Phi>200 \mathrm{kV}$.

In the given simulation we also used the Vorobjev and Yagodkina (2008) empirical model for high-energy particle precipitation that was developed in the Polar Geophysical Institute, Apatity, Russia. In this model, the energy and energy flux of precipitating electrons depend on a 1 min AL index. The GSM TIP model input parameters, such as cross-polar cap potential, location of the polar cap, values and position of the Region 2 field aligned currents and using the climatological model of particle precipitation are not simple variables. These model input parameters have complex spatial and temporal resolution. Also, the thermosphere-ionosphere system is a very complex coupled medium. Therefore, it is a very challenging task to select the spatial and temporal variations in the model input parameters for any particular storm, and such a specific selection could provide improved model simulation results only for this particular storm event. One of the main goals of our paper is to demonstrate the possibility of general statement of the problem of thermosphere-ionosphere response to geomagnetic storm using the coupled thermosphere-ionosphere-electrodynamics model (GSM TIP) with input parameters from different empirical models. Such a statement of the problem has been continuously improved by our group over the last 6 years (Klimenko et al., 2011a, c, 2015a; Bessarab et al., 2015; Suvorova et al., 2016; Dmitriev et al., 2017) and may be used for different geomagnetic storm cases.

In this paper we used the described statement of the problem for interpretation of the observed ionospheric disturbances during geomagnetic storms on 26-30 September 2011. As a reference level for all thermospheric and ionospheric parameters we selected calculation results for the quiet day of 24 September 2011, when low geomagnetic activity was observed. Solar activity during that day was the same as for the entire period.

\section{Results}

We have analyzed the ionosphere response to the geomagnetic storms of 26-30 September 2011 using the GSM TIP simulations with the same model input parameters (Klimenko et al., 2015a; Kotova et al., 2015). Using the Irkutsk ionosonde data, Klimenko et al. (2015a) reported an occurrence of the positive effects in electron density at midlatitudes during the storm recovery phase. These effects were caused by an increase in the $n(\mathrm{O}) / n\left(\mathrm{~N}_{2}\right)$ ratio. We have also demonstrated that the model simulation results can also be applied for the medium description in the radio wave propagation tasks. Kotova et al. (2015) present model results of ray tracing changes during this storm event using the GSM TIP and IRI models. Here, we consider the latitudinal distribution of the storm-time foF 2 and TEC effects along three different longitudes. Special attention is paid to the latitudinal extent and temporal evolution of the positive effects in foF 2 and TEC during the recovery phase of these geomagnetic storms.

Figure 2 shows the foF2 variations over Irkutsk and Kaliningrad stations during 26-30 September 2011 as deduced from the vertical sounding data and the GSM TIP model simulation. Over Irkutsk during the main phase of the geomagnetic storm on 26 September 2011, the positive foF2 disturbances occurred in the evening sector. These effects were further replaced by the negative disturbances at night. The negative effects in foF 2 occurred on the recovery phase of geomagnetic disturbances, on 28 September, whereas on 29-30 September they are replaced by the daytime positive and nighttime negative disturbances in $f o \mathrm{~F} 2$. It is clear that the largest daytime positive disturbance on 29 September exceeds $\sim 3$ times the ordinary day-to-day variation. Based on the satisfactory qualitative agreement between the simulation results and observations, we are able to explore the formation mechanisms of the ionospheric disturbances during the main phase of the geomagnetic storm on 26 September and recovery phases of geomagnetic disturbances on 2930 September. Based on the results over Irkutsk, Klimenko et al. (2015a) concluded that (1) the main mechanism of the positive disturbances in $f o \mathrm{~F} 2$ in sunlit hours during the main phase is the storm-time equatorward wind that pushes plasma upward to the higher altitudes of slow molecular recombination (this result confirmed the theory of Mayr et al., 1978); (2) after the positive effects in foF2 during the storm's main phase, the plasmaspheric flux tubes are depleted at the middle latitudes due to changes in the neutral composition of the thermosphere and expansion of the magnetospheric convection to middle latitudes, which is a common feature for all storms (Schunk and Nagy, 2000); (3) the positive daytime disturbances in $f_{o} \mathrm{~F} 2$ during the storm's recovery phase are formed by increasing $n(\mathrm{O}) / n\left(\mathrm{~N}_{2}\right)$ (this is new result that has never been discussed); and (4) negative nighttime effects in $f_{o} \mathrm{~F} 2$ are associated with underfilling flux tubes depleted during the main phase (Carpenter and Park, 1973; Krinberg and Tashchilin, 1982), which leads to a decrease in plasma flows from the plasmasphere to support the nighttime ionosphere. If, in general, the behavior of the $f_{o} \mathrm{~F} 2$ disturbances in model simulations and observational data are in rather good agreement, the disturbance magnitude in observations will be much larger than in the model, particularly for the case of the negative perturbation on 27 September 2011. According to the model calculations for this day, there is no sharp decrease in the critical frequency during the main phase on 27 September, which was recorded in observations. In our opinion, significant negative disturbances in $f_{o} \mathrm{~F} 2 \mathrm{ob}-$ served at middle latitudes during daytime hours are related mainly to ion losses due to recombination caused by the neutral atmosphere composition changes associated with heating of the high-latitude thermosphere during geomagnetic storms. It is very important to highlight that the differences in foF2 disturbances over Kaliningrad and Irkutsk are qualitatively reproduced by GSM TIP model results: the presence of 

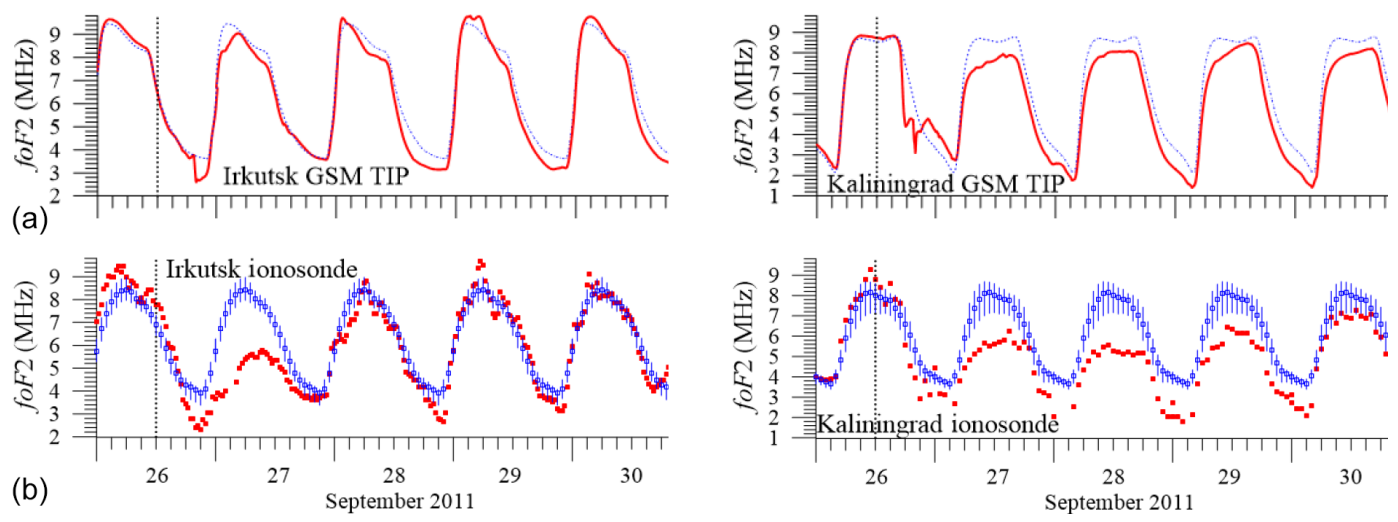

Figure 2. Variations in the $f o F 2$ (red) above Irkutsk and Kaliningrad during 26-30 September 2011: (a) the GSM TIP calculation results and (b) ionosonde data. Blue shows the quiet geomagnetic conditions, with 27-day median and interquartile range bars for ionosonde observations.

(a)

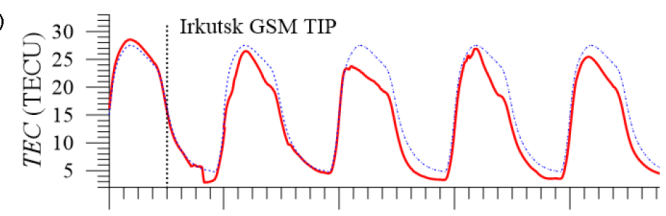

(b)

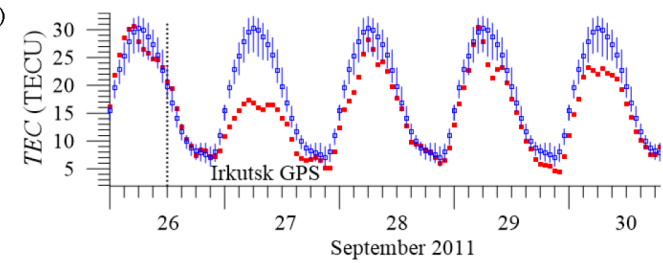

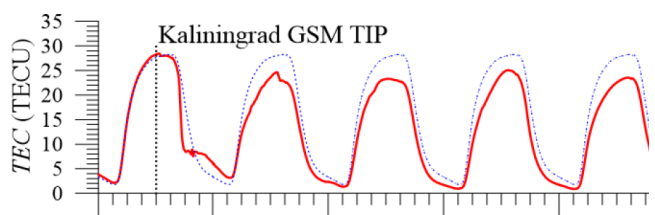

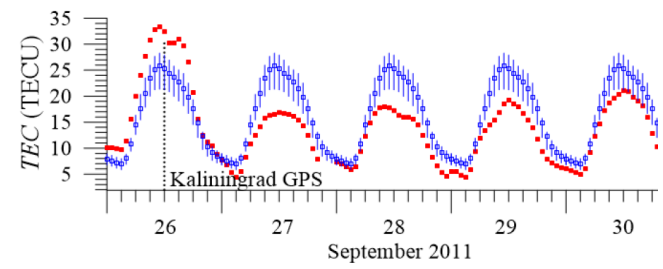

Figure 3. The same as in Fig. 2, but for the TEC calculated from the GSM TIP and derived from the GPS receiver.

only negative $f o \mathrm{~F} 2$ disturbances over Kaliningrad during 28 30 September in comparison to daytime positive and nighttime negative disturbances in $f o \mathrm{~F} 2$ over Irkutsk during this period. Such a longitudinal difference may be explained by several factors. Firstly, there is a difference in local time between Kaliningrad and Irkutsk during different storm phases. Secondly, Kaliningrad is located at a higher geomagnetic latitude than Irkutsk, which means a closer position of Kaliningrad to a heating source at the auroral region during geomagnetic storms.

Figure 3 shows the diurnal TEC variations over Irkutsk and Kaliningrad in quiet conditions and during the geomagnetic storm. These results were derived from the GSM TIP model simulations and from the GPS signal measurements of the GPS stations in Irkutsk and Kaliningrad. Comparison of Figs. 2 and 3 leads to the following conclusions: (1) the disturbances in $f o \mathrm{~F} 2$ and TEC have the same sign during the main phases on 26 and 27 September and at nighttime during the recovery phase, and (2) the largest differences between the disturbances in $f o \mathrm{~F} 2$ and TEC were observed in daytime during the recovery phase. During the main phase of the storm on 26 September 2011, the behavior of the crit- ical frequency $f o \mathrm{~F} 2$ over Irkutsk, as well as TEC, demonstrated a clear negative effect, which was more pronounced in $f o F 2$ than in TEC - i.e., during the main phase the midlatitude ionosphere was more changeable than the plasmasphere. In contrast the behavior of $f o \mathrm{~F} 2$ and TEC over Kaliningrad demonstrated a clear positive effect during the main phase of the storm on 26 September 2011. These disturbances were more pronounced in TEC than in $f o \mathrm{~F} 2$ - i.e., the sub-auroral ionosphere is less changeable in comparison with the plasmasphere during the main phase. During the recovery phase the TEC perturbations were always negative, even in the daytime, while the daytime positive disturbances appear in $f o \mathrm{~F} 2$ over Irkutsk. However, from day to day this negative effect in the TEC values decreases with an increase in the positive effect in $f o \mathrm{~F} 2$.

As seen from Figs. 2 and 3, the GSM TIP simulations agree qualitatively with the observations both for Irkutsk and Kaliningrad. At the same time, the GSM TIP noticeably underestimates the magnitude of negative disturbances. This discrepancy is more pronounced for Kaliningrad, where the disturbances are negative throughout the 27-30 September interval, in contrast to Irkutsk. The greater model-data mis- 

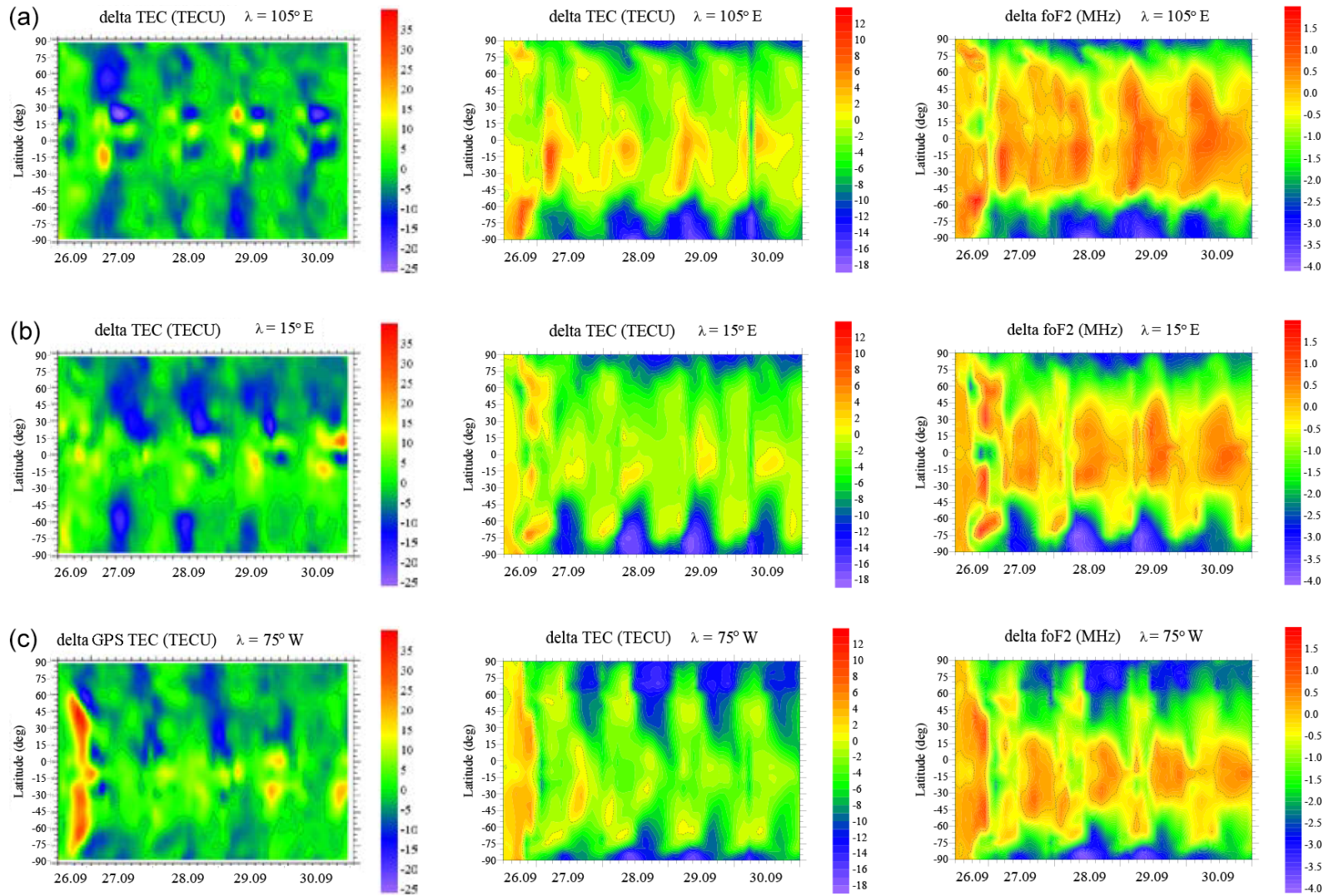

Figure 4. Behavior of the GPS TEC disturbances, and the GSM TIP model-derived disturbances in TEC and foF2 during geomagnetic storms on 26-30 September 2011 at the longitude of $105^{\circ} \mathrm{E}(\mathbf{a}), 15^{\circ} \mathrm{E}(\mathbf{b})$, and $75^{\circ} \mathrm{W}$ (c).

match for Kaliningrad than for Irkutsk can be explained by the higher geomagnetic latitude of Kaliningrad and therefore its closer position to the high-latitudinal energy inputs from the magnetosphere. Obviously, the model-data discrepancy is associated with an underestimation of changes in the neutral composition of the thermosphere and smaller expansion of the magnetospheric convection to middle latitudes. One of the possible reasons of such underestimation may be insufficient heating of the high-latitude thermosphere due to particle precipitation and Joule heating in the model calculations. This could be due to the low precision and simplified nature of the input parameters for the electric field calculation in the GSM TIP model (cross-polar cap potential, location of the polar cap, values and position of the region 2 fieldaligned currents), using the climatological model of particle precipitation and dipole geomagnetic field approximation in the GSM TIP model.

Figure 4 presents evolution of the storm-time disturbances in observations and simulated results as a function of geographical latitude and time during the geomagnetic storms on 26-30 September 2011. Here, we analyze the meridional slices (latitudinal profiles) of the TEC disturbances derived from the GPS observations (GIMs) and together with disturbances in TEC and $f o \mathrm{~F} 2$ calculated by the GSM TIP model. The results are shown at three specific longitudes of $105,15^{\circ} \mathrm{E}$, and $75^{\circ} \mathrm{W}$, which represent the east Siberian, European and American sectors, respectively. The modelcalculated TEC disturbances in general are qualitatively consistent with the GPS TEC observation. Both model simulation results and observations reveal the negative TEC disturbances propagating equatorward from high latitudes. This effect was observed at all considered longitudes. The main difference between model results and observation is the smaller values of negative TEC disturbances in the model results, especially on 27 September 2011. The reason for these discrepancies was discussed above. During the main phase of the geomagnetic storm on 26 September we observed and reproduced the following using the GSM TIP model: (1) the essential positive daytime disturbances in TEC at the American longitudinal sector, (2) the pre-dusk mid-latitude positive effects at $105^{\circ} \mathrm{E}$ are replaced by the strong negative TEC disturbances almost at all latitudes, and (3) a number of nonessential positive and negative disturbances at the European sector.

During 27-30 September 2011 the negative TEC disturbances occurred at practically all longitudes and latitudes except for some areas of positive daytime TEC disturbances near the Equator. These negative TEC disturbances were 

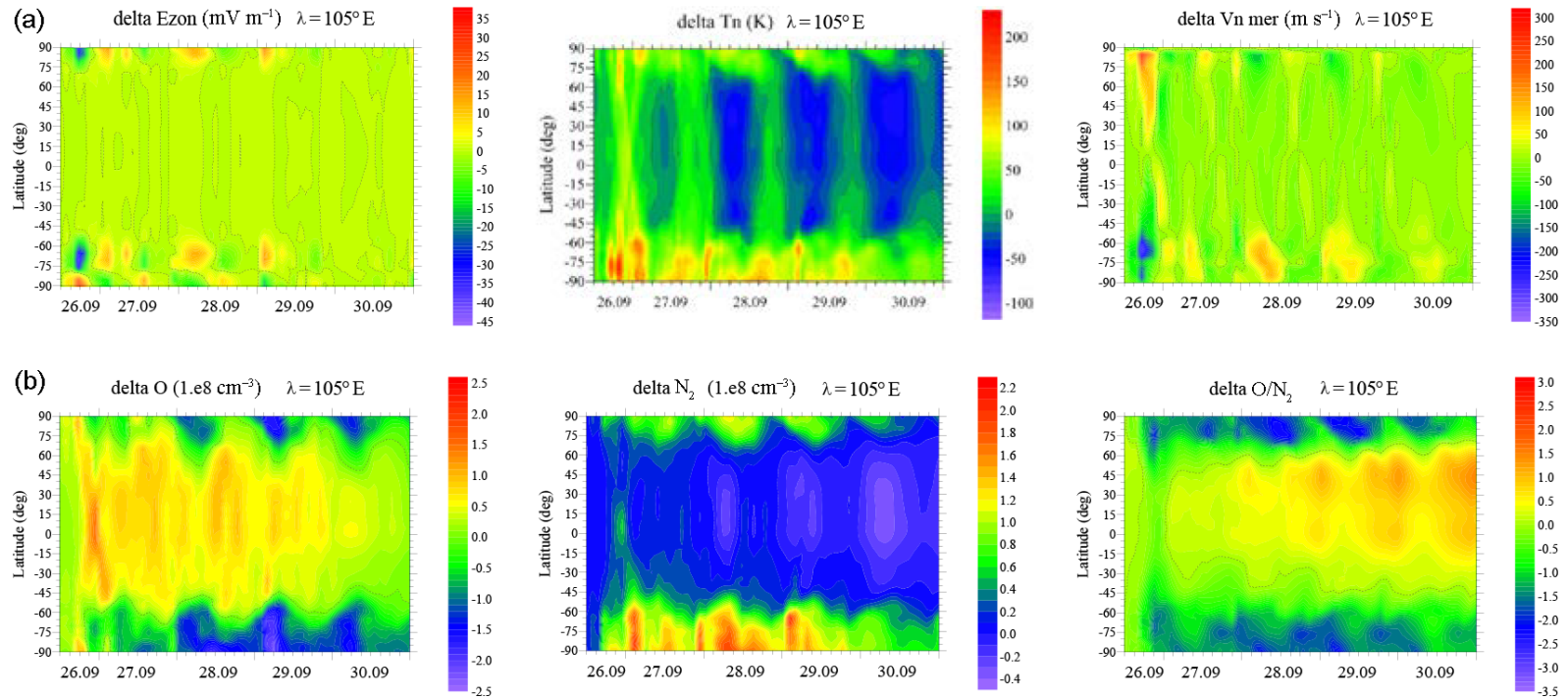

Figure 5. Behavior of the GSM TIP model-derived disturbances in zonal electric field, neutral temperature and meridional velocity of the thermospheric wind (a), $n(\mathrm{O}), n\left(\mathrm{~N}_{2}\right)$ and $n(\mathrm{O}) / n\left(\mathrm{~N}_{2}\right)$ (b) at the height of $300 \mathrm{~km}$ during geomagnetic storms on 26-30 September 2011 at the longitude of $105^{\circ} \mathrm{E}$.

(a) delta Ezon $\left(\mathrm{mV} \mathrm{m}^{-1}\right) \quad \lambda=15^{\circ} \mathrm{E}$

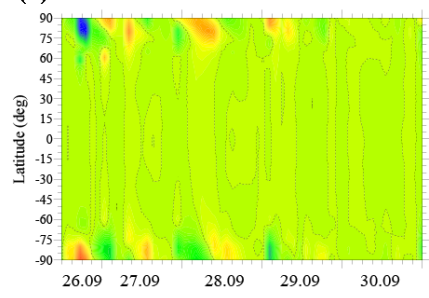

(b)

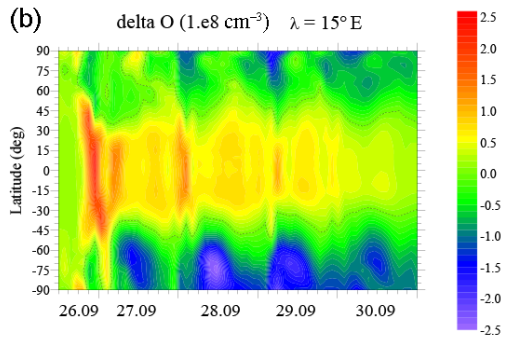

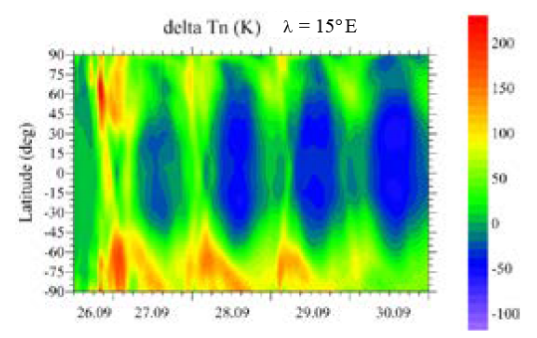
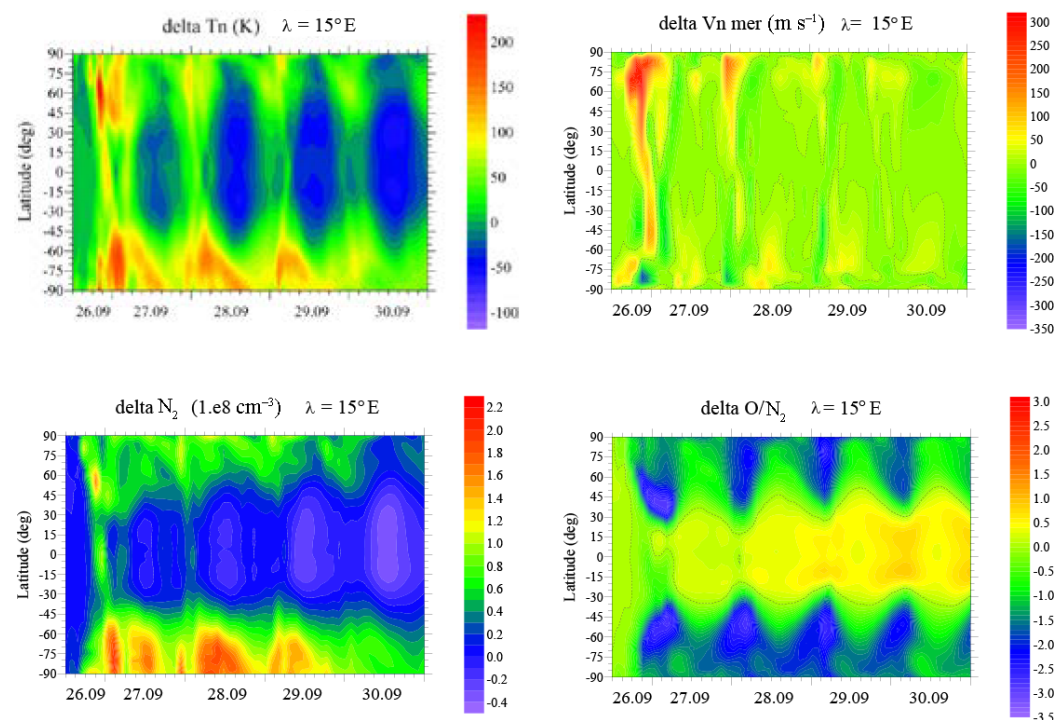

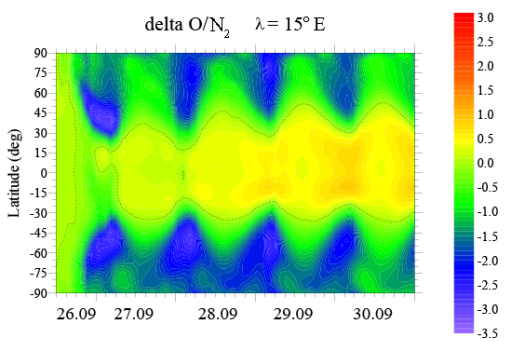

Figure 6. The same as in Fig. 5, but for $15^{\circ} \mathrm{E}$ longitude.

greater at the American longitudinal sector and were much smaller at $105^{\circ} \mathrm{E}$, where the most pronounced positive disturbances were observed. We found that the disturbances in TEC and foF 2 are similar, especially during the main phase of geomagnetic storms. However, they are not correlated - at the same latitude and time, the disturbances in TEC and $f_{o} \mathrm{~F} 2$ may have the different sign, especially at daytime during the recovery storm phase. We should note the formation of the negative disturbances in TEC and foF 2 at high latitudes and the positive disturbances at lower latitudes and at the Equator. An interesting feature of the storm-time ionospheric effects in the vicinity of the geomagnetic equator is the formation of positive daytime disturbances simultaneously in $f o \mathrm{~F} 2$ and TEC on 26 and 27 September. The positive daytime disturbances were still observed in foF2 during 27-30 September, whereas the negative disturbances occurred in TEC. In this case, the low- and mid-latitude positive disturbances in $f_{o} \mathrm{~F} 2$ span to a broader spatial region in comparison to the positive disturbances in TEC. The largest latitudinal extent of the positive disturbances in $f o \mathrm{~F} 2$ occurred at $105^{\circ} \mathrm{E}$, and the smallest one at $75^{\circ} \mathrm{W}$. It should be emphasized that, during the recovery phase of the geomagnetic storms, the positive disturbances in foF 2 occur in the daytime mid-latitude iono- 

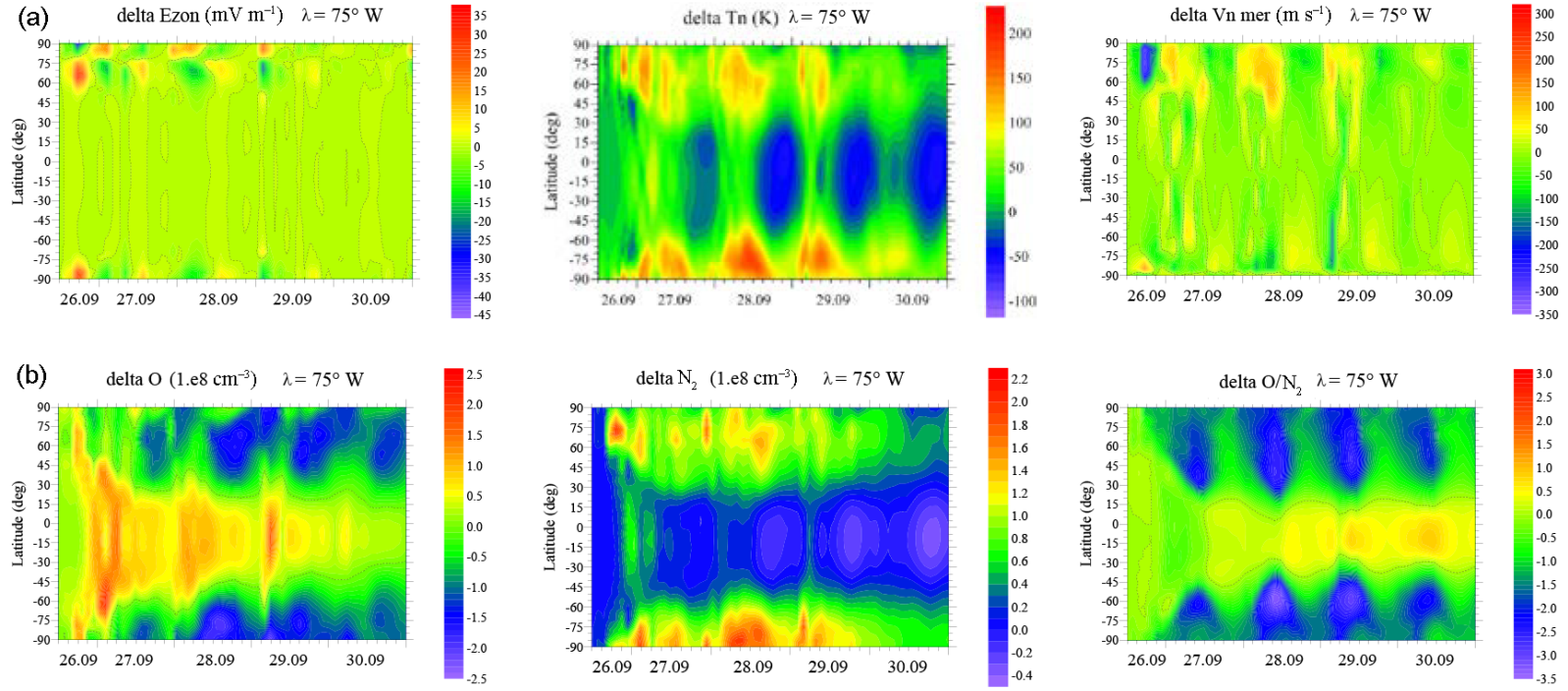

Figure 7. The same as in Fig. 5, but for the longitude of $75^{\circ} \mathrm{W}$.

sphere, but at night the formation of the negative effects appears.

Figures 5, 6 and 7 present the latitudinal profiles of the GSM TIP simulation results at three selected longitudes of $105,15^{\circ} \mathrm{E}$, and $75^{\circ} \mathrm{W}$, respectively. They are disturbances in zonal electric field, neutral temperature, meridional neutral wind, and thermospheric composition $\left(n(\mathrm{O}), n\left(\mathrm{~N}_{2}\right)\right.$, $\left.n(\mathrm{O}) / n\left(\mathrm{~N}_{2}\right)\right)$ calculated for height of $\sim 300 \mathrm{~km}$. The effects of eastward electric field can explain the positive ionospheric disturbances in TEC and $f o \mathrm{~F} 2$ at the initial storm phase on 26 September (during the first few hours). The maximal effects of the positive ionospheric storm in $f o \mathrm{~F} 2$ and TEC occurred at $\sim 20$ :00 UT ( $8 \mathrm{~h}$ after the SSC) in the American sector, $75^{\circ} \mathrm{W}$. We explain these effects by means of the well-known chain of phenomena in the thermosphere during storms (Mayr et al., 1978) and confirm model results using the GSM TIP (Figs. 6 and 7). During geomagnetic storms the strengthening of the high-latitude ionospheric electric fields, currents and auroral particle precipitation causes thermospheric heating. This heating drives an additional equatorward neutral wind that supports an increase in the F-region electron density at middle and low latitudes. These effects of the neutral wind at different latitudes can explain the formation of the long-lasting positive ionospheric storm. At the same time, the significant in the neutral atmosphere composition change inhibit the formation of the positive disturbances in $f o \mathrm{~F} 2$ and TEC.

The thermospheric heating at high latitudes increases the scale height of all neutral species including molecular nitrogen, which in turn leads to a decrease in the $n(\mathrm{O}) / n\left(\mathrm{~N}_{2}\right)$ ratio and consequently electron density at the ionospheric Fregion heights. The additional equatorward wind driven by the same thermospheric heating also leads to the atomic oxygen transport toward the middle and equatorial latitudes with greater velocity than the transport velocity of the molecular thermospheric species. During the equinox conditions, this atomic oxygen transport happens in a similar manner in the Northern and Southern Hemisphere. At the F-region heights, atomic oxygen is the dominant neutral component. Therefore, this process leads not only to an increase in $n(\mathrm{O})$ at middle and low latitudes but also to an increase in the total neutral density in these spatial areas. This in turn, in the presence of weakly varying daytime source of the neutral heating, should lead to a neutral cooling at middle and low latitudes, and consequently to the reduction of the scale height of the neutral species, including molecular nitrogen. This is the main reason for the decrease in $n\left(\mathrm{~N}_{2}\right)$ at low latitudes during the recovery phase of geomagnetic storm on 28,29 , and 30 September. The increase in $n(\mathrm{O})$ and decrease in $n\left(\mathrm{~N}_{2}\right)$ lead to a significant enhancement in $n(\mathrm{O}) / n\left(\mathrm{~N}_{2}\right)$ ratio at low and equatorial latitudes. These results contradict the mechanism proposed by Lynn et al. (2004), in which the negative disturbances in $n(\mathrm{O}) / n\left(\mathrm{~N}_{2}\right)$ ratio are transported from the high latitudes to the Equator. Such changes in the neutral atmosphere composition, in our opinion, are the main source for the daytime positive disturbances in $f o \mathrm{~F} 2$ at low latitudes during the recovery phase of this storm (27-30 September). These results are confirmed by the comparison of the disturbances in $n(\mathrm{O}) / n\left(\mathrm{~N}_{2}\right)$ and $f o \mathrm{~F} 2$ at different longitudes. It is evident that the largest area of positive $n(\mathrm{O}) / n\left(\mathrm{~N}_{2}\right)$ occurs at $105^{\circ} \mathrm{E}$, which is in agreement with the largest positive disturbances in $f o \mathrm{~F} 2$. For this particular storm we did not find the essential electric field disturbances during the recovery storm phases. Such results may be explained by the moderate level of geomagnetic activity during considered geomagnetic storms, which leads to the non-essential disturbances in wind velocity at the lower thermosphere, which is the main process in formation of disturbance dynamo electric field. 

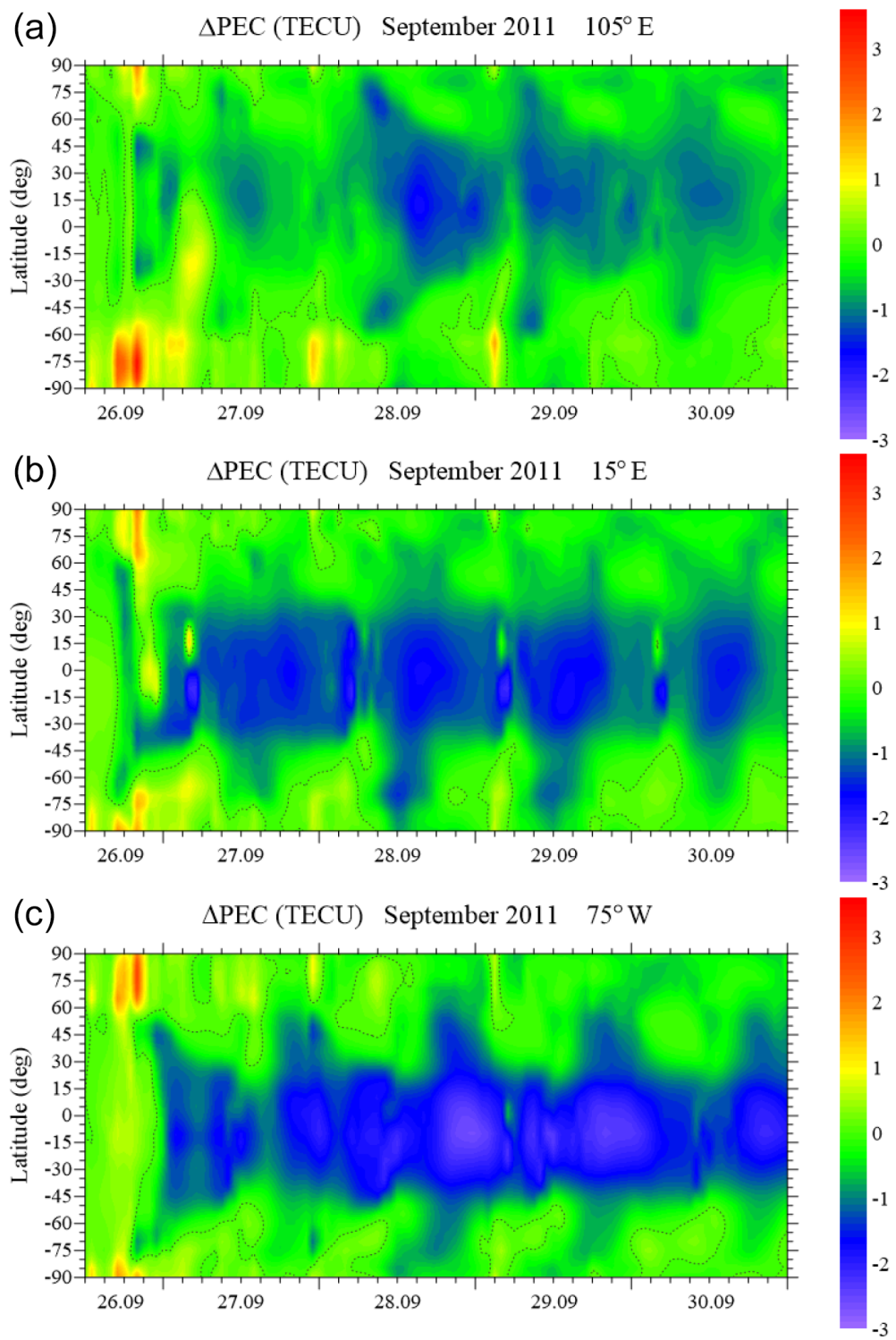

Figure 8. Behavior of the GSM TIP model-derived PEC (electron content in the altitudinal range 800-20000 km) disturbances during geomagnetic storms on 26-30 September 2011 at the longitude of $105^{\circ} \mathrm{E}$ (a), $15^{\circ} \mathrm{E}$ (b), and $75^{\circ} \mathrm{W}$ (c).

The mechanical effects of neutral wind lead to (1) reduction (or termination) in the downward plasma diffusion along the geomagnetic field lines and (2) uplifting of the ionosphere to higher altitudes with reduced chemical loss rates and, hence, plasma accumulation at heights near and above the ionospheric $\mathrm{F} 2$ peak centered at around $\pm 30^{\circ}$ magnetic latitude. According to the GSM TIP model results, the prompt penetration of eastward electric field dominates in producing the positive ionospheric storm only after storm onset, and equatorward neutral wind dominates during the main phase and several hours after that. However, we conclude that during the recovery phase the neutral composition changes play the most important role in the daytime electron density increase at low latitudes.
Under nighttime conditions, the main source (solar radiation) of heating and ionization at low latitudes is absent; therefore, (1) an increase in $n(\mathrm{O})$ at the F-region heights by itself does not lead to an increase in electron density, and (2) an increase in total neutral density due to increase in $n(\mathrm{O})$ at the F-region heights at low latitudes does not lead to additional cooling, hence, it does not change $n\left(\mathrm{~N}_{2}\right)$ and, as a consequence, to the chemical loss rates in ion-molecular reactions. This can explain the absence of the storm-time positive perturbations in $f o \mathrm{~F} 2$ and TEC at nighttime due to changes in the neutral atmosphere composition at the ionospheric Fregion heights. Also, at night the heating in auroral region is transported equatorward from high latitudes. This heating leads to an increase in the $\mathrm{N}_{2}$ scale height, and hence to an in- 


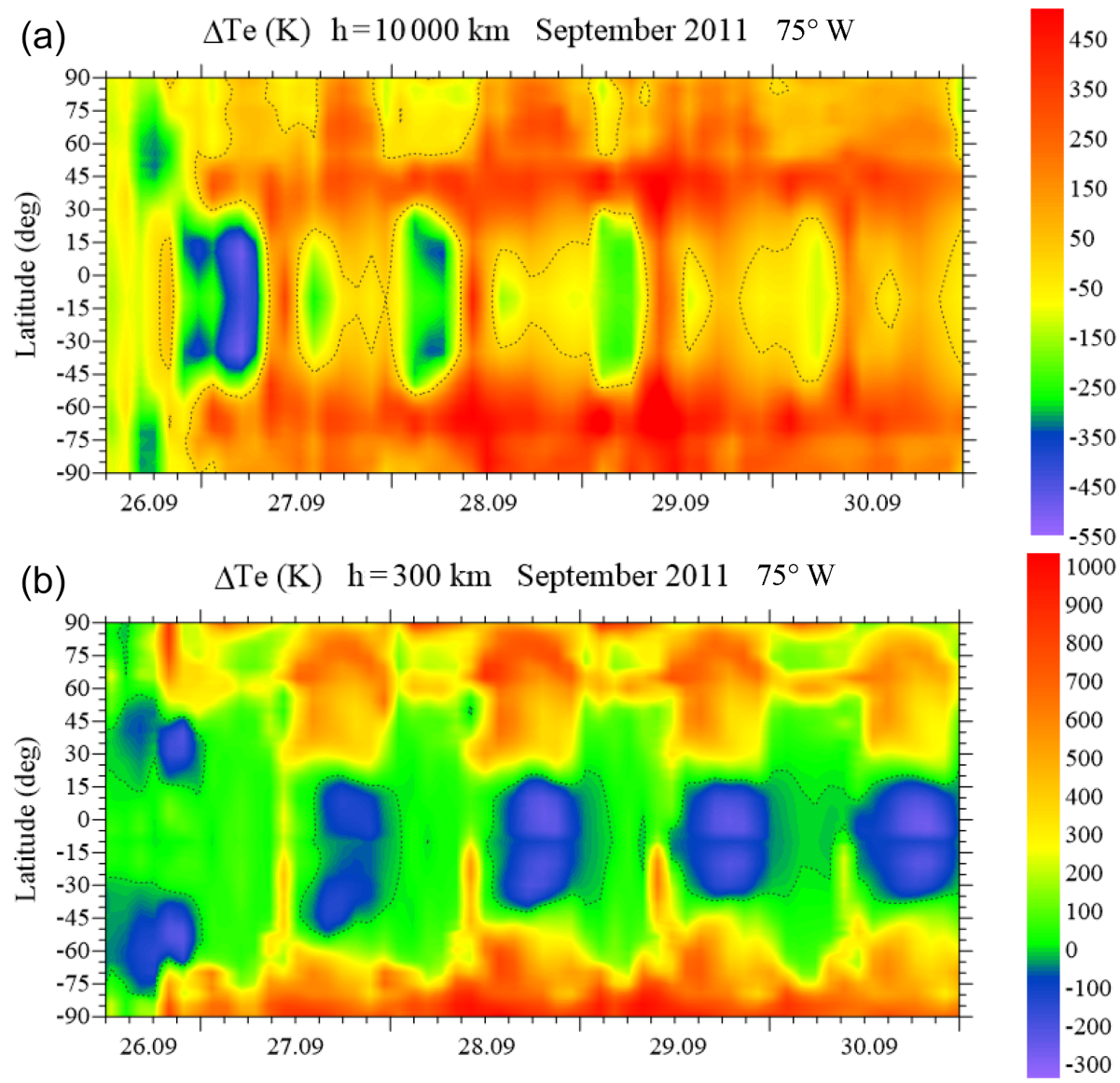

Figure 9. Behavior of the GSM TIP model-derived disturbances in the electron temperature, $T_{\mathrm{e}}$, at the height of $300 \mathrm{~km}(\mathbf{b})$ and $10000 \mathrm{~km}$ (a) during geomagnetic storms on 26-30 September 2011 at the longitude of $75^{\circ} \mathrm{W}$.

crease in $n\left(\mathrm{~N}_{2}\right)$ at heights of the ionospheric $\mathrm{F}$ region, which leads to the nighttime negative disturbances in $f o \mathrm{~F} 2$ and TEC.

The simultaneous formation of the positive disturbances in $f o \mathrm{~F} 2$ and negative disturbances in TEC at low latitudes on 27-30 September 2011 could be explained in the following way. It is known that geomagnetic storms lead to the depletion of the plasma tubes (tubes that are formed by geomagnetic field lines, filled by thermal plasma) (Carpenter and Park, 1973). When geomagnetic activity increases, the plasma tubes deplete. During the recovery phase of the geomagnetic storm, the refilling of plasma tubes originates from the ionospheric source (Carpenter and Park, 1973; Bailey and Moffett, 1978; Krinberg and Tashchilin, 1982). The level of depletion depends on the geomagnetic storms intensity. The time of plasma tubes refilling depends on their volume (Bailey and Moffett, 1978; Krinberg and Tashchilin, 1982). The time for the tube refilling by plasma increases with tube volume and can take several days or even tens of days (Krinberg and Tashchilin, 1982; Rasmussen et al., 1993; Krall and Huba, 2013). The near-equatorial plasma tubes refilled much faster due to their smaller volume. With an increase in the distance from the Equator the degree of filling of the plasma tubes decreases. The vertical TEC is an integral/sum of the electron density for all altitudes up to $20000 \mathrm{~km}$. Plasma tubes with bases at different geomagnetic latitudes contribute to the electron density at different altitudes above the considered location. Plasma tubes with the base at a higher geomagnetic latitude cross higher altitudes. Thus, during the recovery phase of geomagnetic storms the main contribution to TEC at lower altitudes is provided by more filled plasma tubes with bases at lower latitudes. With a height increase the plasma tubes filling level is reduced, which leads to a reduction in the contribution of these tubes into TEC as compared to the values of the quiet-time conditions. During recovery phases, the mechanism of the plasma tube diffusional depletion becomes the main mechanism in the formation of the negative perturbations in TEC. As shown above, there are three mechanisms - equatorward wind, eastward electric field, and an increase in the $n(\mathrm{O}) / n\left(\mathrm{~N}_{2}\right)$ ratio - which lead to the positive disturbances in $f o \mathrm{~F} 2$. At the same time, the perturbations in TEC are caused by the same mechanisms that counteract the mechanism of the plasma tubes diffusional depletion caused by the decrease in the $n(\mathrm{O}) / n\left(\mathrm{~N}_{2}\right)$ ratio at high and middle latitudes. This is the reason for the differ- 
ences between $f_{o} \mathrm{~F} 2$ and TEC disturbances during the geomagnetic storm.

Figure 8 shows the behavior of the model-derived disturbances in vertical electron content at heights of plasmasphere (from 800 to $20000 \mathrm{~km}$ ), PEC (plasmaspheric electron content), as a function of geographic latitude and time during geomagnetic storms on 26-30 September 2011. Meridional slices are constructed for three specific longitudes: 15 , $105^{\circ} \mathrm{E}$ and $75^{\circ} \mathrm{W}$. Immediately after the geomagnetic storm onset the negative PEC perturbation occurred at all considered longitudes and latitudes, except high latitudes, pointing to the processes of the plasma tubes' depletion. The model simulation results support the assumption made above that the negative perturbations in $f o \mathrm{~F} 2$ and TEC at night during the recovery phase are related to depletion of the thermal plasma at the plasmasphere altitudes. In addition, we should note two other interesting results obtained in the model simulation. The first one is the formation of the negative PEC disturbances at middle and low latitudes and positive PEC perturbations in the areas from subauroral latitudes to the poles, where the concurrent negative $f o \mathrm{~F} 2$ perturbations occurred. This finding is consistent with the recent results of Liu et al. (2016), who analyzed behavior of the vertical profiles of electron density over the Millstone Hill ISR during the 17 March 2015 great storm and reported a drop in the electron density at the F2 layer peak and its significant increase at altitudes of the topside ionosphere. The negative effects in electron density within the plasma tubes occurred due to the tubes' depletion as a response to the geomagnetic disturbances. The latitudinal distribution of the PEC disturbances depends on the latitudinal distribution of the electron temperature disturbances, which causes the scale height changes of the ionosphere and plasmasphere. Figure 9 demonstrates an example of the GSM TIP model-derived electron temperature disturbances at 300 and $10000 \mathrm{~km}$ altitude near $75^{\circ} \mathrm{W}$. We obtained the electron heating at the $300 \mathrm{~km}$ altitude at all areas apart from the cooling areas close to the Equator. This electron heating source is produced through the neutral heating by Joule heating and increasing of the energy impact caused by auroral particles precipitations during geomagnetic disturbances. Figures 8-9 demonstrate that the predominate mechanism of the positive PEC disturbances at high latitudes is the electron heating due to rise of the neutral temperature. The neutral heating leads to the negative disturbances in $f o \mathrm{~F} 2$ through the $n\left(\mathrm{~N}_{2}\right)$ increase. Such explanation of opposite disturbances in PEC and $f o \mathrm{~F} 2$ is consistent with the Millstone Hill ISR observations during the March 2015 storm (Liu et al. 2016). The electron cooling at the $300 \mathrm{~km}$ altitude near the Equator can be explained by an increase in $n(\mathrm{O})$ and the neutral temperature decrease (Fig. 7). The resulted electron temperature disbalance at the F-layer heights through thermal conductivity leads to the cooling effects at the plasmaspheric heights (Fig. 9a). The electron temperature changes lead to an increase in the ionospheric electron scale height globally but excluding the equatorial area. A de- crease in the electron scale height in the topside ionosphere and plasmasphere occurs in the equatorial region (Fig. 8), which leads to negative effects in PEC. The second important result is a significant difference in magnitude and duration of the negative PEC disturbances between the three considered longitudinal sectors. The largest are ones in the American longitudinal sector and the smallest ones in the east Siberian longitudinal sector. This can be explained by the fact that, at the American longitudinal sector, the points with the same geographical latitudes in the Northern Hemisphere are found at larger L shells than in the east Siberian sector; thus, here, the plasma tubes have a larger volume and it takes more time to refill them after their depletion at the initial stage of the geomagnetic storms. Therefore, the plasma tubes in the east Siberian sector have a smaller volume and are filled very quickly (Fig. 8).

\section{Conclusions}

This study, based on both observational and model simulation results, presents a comprehensive analysis of the ionospheric disturbances during the main and recovery phases of the geomagnetic storms that occurred on 26-30 September 2011. The main phase of the geomagnetic storm leads to the essential long-lasting positive disturbances in TEC and $f o \mathrm{~F} 2$ at the daytime American longitudinal sector and predusk mid-latitude east Siberian region mainly due to stormtime equatorward neutral wind. Effects of eastward electric field can explain the short-term positive ionospheric storm in TEC and foF 2 only during the first few hours at the initial storm stage. The negative disturbances in TEC and $f o \mathrm{~F} 2$ at high latitudes are formed due to a decrease in the $n(\mathrm{O}) / n\left(\mathrm{~N}_{2}\right)$ ratio during practically the whole storm-time period. At night, in spite of the decrease in $n\left(\mathrm{~N}_{2}\right)$, the negative effects in $f o \mathrm{~F} 2$ at middle and low latitudes are formed due to underfilling of the plasma tubes as a result of their depletion during the main phase of the geomagnetic storm.

The GSM TIP simulations agree qualitatively with the observations both for Irkutsk and Kaliningrad, but at the same time there are noticeable quantitative differences manifested in the underestimated magnitudes of negative disturbances. An improved agreement between the model and observations for the given storm case could potentially be achieved through an appropriate selection of the spatial and temporal variation in the model input parameters, but this was not the goal of the present paper. Nevertheless, we have demonstrated the possibility of a general statement regarding the problem of the thermosphere-ionosphere system response to geomagnetic storm using a coupled thermosphereionosphere-electrodynamics model (GSM TIP) with input parameters from different empirical models, which was one of the main goals of our paper. The mentioned statement of the problem has been continuously improved by our group over the last 6 years (Klimenko et al., 2011a, c, 2015a; 
Bessarab et al., 2015; Suvorova et al., 2016; Dmitriev et al., 2017) and may be used for different geomagnetic storm cases. We should also note that first-principle model results are intended to illustrate how the different sources operate and produce the ionospheric response to geomagnetic storms.

We emphasize the new results - formation of the positive daytime disturbances in $f o \mathrm{~F} 2$ and TEC at middle and low latitudes and at the Equator due to $n(\mathrm{O}) / n\left(\mathrm{~N}_{2}\right)$ enhancement during the latest stage of the main phase and during the recovery phase (at that, the latitudinal extent and duration of $f o \mathrm{~F} 2$ disturbances are greater than TEC). The spatial extent of this new phenomenon depends on the longitudinal sector: for the geomagnetic storm on 26-30 September 2011 this effect was more significant at the east Siberian longitudinal sector and it was practically absent at the American sector.

The comparison of the model-derived $f o F 2$, PEC and TEC disturbances allowed us to make the following conclusions:

1. During the main phase of the geomagnetic storm the $f o \mathrm{~F} 2$ behavior demonstrates a more pronounced negative effect than TEC; the ionosphere is more changeable in comparison with the plasmasphere during the main phase of the geomagnetic storm.

2. The largest differences between the storm-time disturbances in $f_{o F} 2$ and TEC were found in both observations and simulation results at middle and low latitudes during the storm recovery phase, when the negative TEC perturbations can occur simultaneously with the positive disturbances in $f o \mathrm{~F} 2$.

3. The simultaneous formation of the positive disturbances in $f o \mathrm{~F} 2$ and negative disturbances in TEC at low latitudes during the recovery phase is explained by the counteraction between mechanisms that lead to the positive disturbances in $f o \mathrm{~F} 2$ (namely, an increase in the $n(\mathrm{O}) / n\left(\mathrm{~N}_{2}\right)$ ratio) and to the negative perturbations in PEC and TEC (the plasma tube diffusional depletion and electron cooling).

4. The positive disturbances in the electron content at plasmaspheric heights $(800-20000 \mathrm{~km})$ at high latitudes can appear simultaneously with the negative disturbances in TEC and $f o F 2$ due to electron and neutral temperature heating.

Data availability. GSM TIP model results and different kind of presented observation data are available from the authors upon request.

Competing interests. The authors declare that they have no conflict of interest.
Special issue statement. This article is part of the special issue "The 14th International Symposium on Equatorial Aeronomy". It is a result of the 14th International Symposium on Equatorial Aeronomy, Bahir Dar, Ethiopia, 19-23 October 2015.

Acknowledgements. The geomagnetic indices were obtained from the World Data Center for Geomagnetism, Kyoto (http://wdc.kugi. kyoto-u.ac.jp/). We are grateful to the International GNSS Service (IGS) for raw GPS data and GIM products. This investigation was performed with the financial support of the Russian Science Foundation grant (no. 17-17-01060). Experimental data over Irkutsk were recorded by the Angara Multiaccess Center facilities at ISTP SB RAS. The Kaliningrad ionospheric data analysis and interpretation during geomagnetic storm were supported by the program "5-100" to improve competitiveness of I. Kant Baltic Federal University.

The topical editor, Duggirala Pallamraju, thanks Nirvikar Dashora, Ana G. Elias, and three anonymous referees for help in evaluating this paper.

\section{References}

Afraimovich, E. L., Astafyeva, E. I., Kosogorov, E. A., and Yasyukevich, Yu. V.: The mid-latitude field-aligned disturbances and its impact on differential GPS and VLBI, Adv. Space Res., 47, 1804-1813, https://doi.org/10.1016/j.asr.2010.06.030, 2011.

Astafyeva, E., Zakharenkova, I., and Förster, M.: Ionospheric response to the 2015 St. Patrick's Day storm: A global multiinstrumentl overview, J. Geophys. Res.-Space, 120, 9023-9037, https://doi.org/10.1002/2015JA021629, 2015.

Bailey, G. J. and Moffett, R. J.: Interhemispheric flow of thermal plasma in a closed magnetic flux tube at mid-latitudes under sunspot minimum conditions, Planet. Space Sci., 26, 733-763, https://doi.org/10.1016/0032-0633(78)90006-5, 1978.

Balan, N., Otsuka, Y., Tsugawa, T., Miyazaki, S., Ogawa, T., and Shiokawa, K.: Plasmaspheric electron content in the GPS ray paths over Japan under magnetically quiet conditions at high solar activity, EPS, 54, 71-79, https://doi.org/10.1186/BF03352423, 2002.

Balan, N., Alleyne, H., Otsuka, Y., Vijaya Lekshmi, D., Fejer, B. G., and McCrea, I.: Relative effects of electric field and neutral wind on positive ionospheric storms, EPS, 61, 439-445, https://doi.org/10.1186/BF03353160, 2009.

Balan, N., Shiokawa, K., Otsuka, Y., Kikuchi, T., Vijaya Lekshmi, D., Kawamura, S., Yamamoto, M., and Bailey, G. J.: A physical mechanism of positive ionospheric storms at low latitudes and midlatitudes, J. Geophys. Res., 115, A02304, https://doi.org/10.1029/2009JA014515, 2010.

Balan, N., Otsuka, Y., Nishioka, M., Liu, J. Y., and Bailey, G. J.: Physical mechanisms of the ionospheric storms at equatorial and higher latitudes during the recovery phase of geomagnetic storms, J. Geophys. Res., 118, 2660-2669, https://doi.org/10.1002/jgra.50275, 2013.

Bessarab, F. S., Korenkov, Yu. N., Klimenko, V. V., Klimenko, M. V., and Zhang, Y.: E-region ionospheric storm on May 1-3, 2010: GSM TIP model representation and sugges- 
tions for IRI improvement, Adv. Space Res., 55, 2124-2130, https://doi.org/10.1016/j.asr.2014.08.003, 2015.

Buonsanto, M. J.: Ionospheric storms: A review, Space Sci. Rev., 88, 563-601, https://doi.org/10.1023/A:1005107532631, 1999.

Carpenter, D. L. and Park, C. G.: On what ionospheric workers should know about the plasmapauseplasmasphere, Rev. Geophys. Space Ge., 11, 133-154, https://doi.org/10.1029/RG011i001p00133, 1973.

Chen, C. H., Lin, C. H., Matsuo, T., Chen, I. Lee, T., Liu, J. Y., Lin, J. T., and Hsu C. T.: Ionospheric data assimilation with thermosphere-ionosphere-electrodynamics general circulation model and GPS-TEC during geomagnetic storm conditions, J. Geophys. Res.-Space, 121, 5708-5722, https://doi.org/10.1002/2015JA021787, 2016.

Cheng, Z. W., Shi, J. K., Zhang, T. L., Dunlop, M., and Liu, Z. X.: Relationship between $F A C$ at plasma sheet boundary layers and $A E$ index during storms from August to October 2001, Sci. China Ser. E, 51, 842-848, https://doi.org/10.1007/s11431-008-0058-0, 2008.

Cherniak, Iu. V., Zakharenkova, I. E., Krankowski, A., and Shagimuratov, I. I.: Plasmaspheric electron content derived from GPS TEC and FORMOSAT-3/COSMIC measurements: Solar minimum condition, Adv. Space Res., 50, 427-440, https://doi.org/10.1016/j.asr.2012.04.002, 2012.

Cherniak, Iu. V., Zakharenkova, I. E., Dzubanov, D., and Krankowski, A.: Analysis of the ionosphere/plasmasphere electron content variability during strong geomagnetic storm, Adv. Space Res., 54, 586-594, https://doi.org/10.1016/j.asr.2014.04.011, 2014.

Dmitriev, A. V., Suvorova, A. V., Klimenko, M. V., Klimenko, V. V., Ratovsky, K. G., Rakhmatulin, R. A., and Parkhomov, V. A.: Predictable and unpredictable ionospheric disturbances during St. Patrick's Day magnetic storms of 2013 and 2015 and on 8-9 March 2008, J. Geophys. Res.-Space, 122, 2398-2423, https://doi.org/10.1002/2016JA023260. 2017.

Feshchenko, E. Yu. and Maltsev, Yu. P.: Relations of the polar cap voltage to the geophysical activity, Proc. 26 Annual Seminar "Physics of Auroral Phenomena", Apatity, PGI KSC RAS, 2528 February 2003, 59-61, 2003.

Fuller-Rowell, T., Codrescu, M., Maruyama, N., Fredrizzi, M., Araujo-Pradere, E., Sazykin, S., and Bust, G.: Observed and modeled thermosphere and ionosphere response to superstorms, Radio Sci., 42, RS4S90, https://doi.org/10.1029/2005RS003392, 2007.

Gallagher, D. L., Craven, P. D., and Comfort, R. H.: Global core plasma model, J. Geophys. Res., 105, 18819-18833, 2000.

Gulyaeva, T. L. and Gallagher, D. L.: Comparison of two IRI electron-density plasmasphere extensions with GPS-TEC observations, Adv. Space Res., 39, 744-749, 2007.

Hairston, M. R., Coley, W. R., and Stoneback, R.: Vertical and meridional equatorial ion flows observed by CINDI during the 26 September 2011 storm, J. Geophys. Res.-Space, 118, 52305243, https://doi.org/10.1002/jgra.50411, 2013.

Heelis, R. A., Sojka, J. J., David, M., and Schunk, R. W.: Stormtime density enhancements in the middle latitude dayside ionosphere, J. Geophys. Res., 114, A03315, https://doi.org/10.1029/2008JA013690, 2009.

Heelis, R. A., Makela, J. J., and Basu, Su.: Reply to Tsurutani et al.'s comment on "Storming the Bastille: the effect of electric fields on the ionospheric F-layer" by Rishbeth et al. (2010), Ann. Geophys., 31, 151-152, https://doi.org/10.5194/angeo-31-151-2013, 2013.

Hernández-Pajares, M., Juan, J. M., Sanz, J., Orus, R., GarciaRigo, A., Feltens, J., Komjathy, A., Schaer, S. C., and Krankowski, A.: The IGS VTEC maps: a reliable source of ionospheric information since 1998, J. Geodesy, 83, 263-275, https://doi.org/10.1007/s00190-008-0266-1, 2009.

Huba, J. D., Joyce, G., and Fedder, J. A.: Sami2 is Another Model of the Ionosphere (SAMI2): A new low-latitude ionosphere model, J. Geophys. Res., 105, 23035-23053, https://doi.org/10.1029/2000JA000035, 2000.

Jin, H., Miyoshi, Y., Pancheva, D., Mukhtarov, P., Fujiwara, H., and Shinagawa, H.: Response of migrating tides to the stratospheric sudden warming in 2009 and their effects on the ionosphere studied by a whole atmosphere-ionosphere model GAIA with COSMIC and TIMED/SABER observations, J Geophys. Res., 117, A10323, https://doi.org/10.1029/201 2JA01, 2012.

Karpenko, A. L. and Manaenkova, N. I.: Nonlinear time series analysis of the ionospheric measurements, Geologishe Rundshau, 85, 124-129, https://doi.org/10.1007/BF00192070, 1996.

Khmyrov, G. M., Galkin, I. A., Kozlov, A. V., Reinisch, B. W., McElroy, J., and Dozois, C.: Exploring digisonde ionogram data with SAO-X and DIDBase, Proc. AIP Conf. Radio Sounding and Plasma Physics, 974, 175-185, https://doi.org/10.1063/1.2885027, 2008.

Kikuchi, T., Hasimoto, K. K., and Nozaki, K.: Penetration of magnetospheric electric fields to the equator during a geomagnetic storm, J. Geophys. Res., 113, A06214, https://doi.org/10.1029/2007JA012628, 2008.

Klimenko, M. V. and Klimenko, V. V.: Disturbance dynamo, prompt penetration electric field and overshielding in the Earth's ionosphere during geomagnetic storm, J. Atmos. Solar-Terr. Phys., 90/91, 146-155, https://doi.org/10.1016/j.jastp.2012.02.018, 2012.

Klimenko, M. V., Klimenko, V. V., and Bryukhanov, V. V.: Numerical simulation of the electric field and zonal current in the Earth's ionosphere: The dynamo field and equatorial electrojet, Geomagn. Aeronomy, 46, 457-466, https://doi.org/10.1134/S00167932060 40074, 2006.

Klimenko, M. V., Klimenko, V. V., and Bryukhanov, V. V.: Numerical modeling of the equatorial electrojet UT-variation on the basis of the model GSM TIP, Adv. Radio Sci., 5, 385-392, https://doi.org/10.5194/ars-5-385-2007, 2007.

Klimenko, M. V., Klimenko, V. V., Ratovsky, K. G., and Goncharenko, L. P.: Ionospheric effects of geomagnetic storm sequence on 9-14 September 2005, Geomagn. Aeronomy, 51, 364376, 2011a.

Klimenko, M. V., Klimenko, V. V., Ratovsky, K. G., and Goncharenko, L. P.: Disturbances in the ionospheric $F$-region peak heights in the American longitudinal sector during geomagnetic storms of September 2005, Adv. Space Res., 48, https://doi.org/10.1016/j.asr.2011.06.002, 2011b.

Klimenko, M. V., Klimenko, V. V., Ratovsky, K. G., Goncharenko, L. P., Sahai, Y., Fagundes, P. R., de Jesus, R., de Abreu, A. J., and Vesnin, A. M.: Numerical modeling of ionospheric effects in the middle- and low-latitude $F$ region during geomagnetic storm sequence of 9-14 September 2005, Radio Sci., 46, RS0D03, https://doi.org/10.1029/2010RS004590, 2011c. 
Klimenko, M. V., Klimenko, V. V., and Karpachev, A. T.: Formation mechanism of additional layers above regular $F 2$ layer in the near-equatorial ionosphere during quiet period, J. Atmos. SolarTerr. Phys., 90-91, https://doi.org/10.1016/j.jastp.2012.02.011, 2012.

Klimenko, M. V., Klimenko, V. V., Bessarab, F. S., Ratovsky, K. G., Zakharenkova, I. E., Nosikov, I. A., Stepanov, A. E., Kotova, D. S., Vorobjev, V. G., and Yagodkina, O. I.: Influence of geomagnetic storms of September 26-30, 2011, on the ionosphere and HF radiowave propagation, I. Ionospheric effects, Geomagn. Aeronomy, 55, 744-762, https://doi.org/10.1134/S0016793215050072, 2015a.

Klimenko, M. V., Klimenko, V. V., Ratovsky, K. G., Zakharenkova, I. E., Yasyukevich, Yu. V., Korenkova, N. A., Cherniak, Iu. V., and Mylnikova, A. A.: Mid-latitude Summer Evening Anomaly (MSEA) in F2 layer electron density and Total Electron Content at solar minimum, Adv. Space Res., 1184-1195, https://doi.org/10.1016/j.asr.2015.07.019, 2015 b.

Klimenko, M. V., Klimenko, V. V., Zakharenkova, I. E., and Cherniak, Iu. V.: The global morphology of the plasmaspheric electron content during Northern winter 2009 based on GPS/COSMIC observation and GSM TIP model results, Adv. Space Res., 55, 2077-2085, https://doi.org/10.1016/j.asr.2014.06.02, 2015c.

Korenkov, Yu. N., Klimenko, V. V., Förster, M., Bessarab, F. S., and Surotkin, V. A.: Calculated and observed ionospheric parameters for a Magion-2 passage and EISCAT data on 31 July 1990, J. Geophys. Res., 103, 14697-14710, https://doi.org/10.1029/98JA00210, 1998.

Kotova, D. S., Klimenko, M. V., Klimenko, V. V., Zakharov, V. E., Ratovsky, K. G., Nosikov, I. A., and Zhao, B.: Using IRI and GSM TIP model results as environment for HF radio wave propagation model during the geomagnetic storm occurred on 26-29 September 2011, Adv. Space Res., 56, 2012-2029, https://doi.org/10.1016/j.asr.2015.05.009, 2015.

Krall, J. and Huba, J. D.: SAMI3 simulation of plasmasphere refilling, Geophys. Res. Lett., 40, 2484-2488, https://doi.org/10.1002/grl.50458, 2013.

Krinberg, I. A. and Tashchilin, A. V.: Refilling of geomagnetic force tubes with a thermal plasma after magnetic disturbance, Ann. Geophys., 38, 25-32, 1982.

Lee, H. B., Jee, G., Kim, Y. H., and Shim, J. S.: Characteristics of global plasmaspheric TEC in comparison with the ionosphere simultaneously observed by Jason-1 satellite, J. Geophys. Res., 118, 935-946, https://doi.org/10.1002/jgra.50130, 2013.

Lei, J., Wang, W., Burns, A. G., Solomon, S. C., Richmond, A. D., Wiltberger, M., Goncharenko, L. P., Coster, A., and Reinisch, B. W.: Observations and simulations of the ionospheric and thermospheric response to the December 2006 geomagnetic storm: Initial phase, J. Geophys. Res., 113, 1951-1960, https://doi.org/10.1029/2007JA012807, 2008.

Lei, J., Zhu, Q., Wang, W., Burns, A. G., Zhao, B., Luan, X., Zhong, J., and Dou, X.: Response of the topside and bottomside ionosphere at low and middle latitudes to the October 2003 superstorms, J. Geophys. Res.-Space, 120, 6974-6986, https://doi.org/10.1002/2015JA021310, 2015.

Liu, J., Liu, L., Zhao, B., Wei, Y., Hu, L., and Xiong, B.: High-speed stream impacts on the equatorial ionization anomaly region dur- ing the deep solar minimum year 2008, J. Geophys. Res., 117, A10304, https://doi.org/10.1029/2012JA018015, 2012.

Liu, J., Wang, W., Burns, A., Yue, X., Zhang, S., Zhang, Y., and Huang, C.: Profiles of ionospheric storm-enhanced density during the 17 March 2015 great storm, J. Geophys. Res.Space, 121, 727-744, https://doi.org/10.1002/2015JA021832, 2016.

Liu, J. Y., Tsai, H. F., and Jung, T. K.: Total electron content obtained by using the global positioning system, Terr. Atmos. Ocean. Sci., 7, 107-117, 1996.

Lu, G., Goncharenko, L. P., Richmond, A. D., Roble, R. G., and Aponte, N.: A dayside ionospheric positive storm phase driven by neutral winds, J. Geophys. Res., 113, A08304, https://doi.org/10.1029/2007JA012895, 2008.

Lunt, N., Kersley, L., and Bailey, G. J.: The influence of the protonosphere on GPS observations: Model simulations, Radio Sci., 34, 725-732, https://doi.org/10.1029/1999RS900002, 1999a.

Lunt, N., Kersley, L., Bishop, G. J., and Mazzella Jr., A. J.: The contribution of the protonosphere to GPS total electron content: Experimental measurements, Radio Sci., 34, 1273-1280, https://doi.org/10.1029/1999RS900016, 1999 b.

Lynn, K. J. W., Sjarifudin, M., Harris, T. J., and Le Huy, M.: Combined TOPEX/Poseidon TEC and ionosonde observations of negative low-latitude ionospheric storms, Ann. Geophys., 22, 2837-2847, https://doi.org/10.5194/angeo-22-2837-2004, 2004.

Mannucci, A. J., Tsurutani, B. T., Iijima, B. A., Komjathy, A., Saito, A., Gonzalez, W. D., Guarnieri, F. L., Kozyra, J. U., and Skoug, R.: Dayside global ionospheric response to the major interplanetary events of October 29-30, 2003 "Halloween Storms", Geophys. Res. Lett., 32, L12S02, https://doi.org/10.1029/2004GL021467, 2005.

Maruyama, T., Ma, G., and Nakamura, M.: Signature of TEC storm on 6 November 2001 derived from dense GPS receiver network and ionosonde chain over Japan, J. Geophys. Res., 109, A01314, https://doi.org/10.1029/2004JA010451, 2004.

Mayr, H. G. and Volland, H.: Magnetic storm characteristics of the thermosphere, J. Geophys. Res., 78, 2251-2264, https://doi.org/10.1029/JA078i013p02251, 1973.

Mayr, H. G., Harris, I., and Spencer, N. W.: Some properties of upper atmosphere dynamics, Rev. Geophys., 16, 539-565, https://doi.org/10.1029/RG016i004p00539, 1978.

Mendillo M.: Storms in the ionosphere: Patterns and processes for total electron content, Rev. Geophys., 44, RG4001, https://doi.org/10.1029/2005RG000193, 2006.

Namgaladze, A. A., Korenkov, Yu. N., Klimenko, V. V., Karpov, I. V., Bessarab, F. S., Surotkin, V. A., Glushchenko, T. A., and Naumova, N. M.: Global Model of the Thermosphere-IonosphereProtonosphere System, Pure Appl. Geophys., 127, 219-254, https://doi.org/10.1007/BF00879812, 1988.

Namgaladze, A. A., Förster, M., and Yurik R. Y.: Analysis of the positive ionospheric response to a moderate geomagnetic storm using a global numerical model, Ann. Geophys., 18, 461-477, https://doi.org/10.1007/s00585-000-0461-8, 2000.

Pavlov, A. V. and Pavlova, N. M.: Comparison of modeled electron densities and electron and ion temperatures with Arecibo observations during undisturbed and geomagnetic storm periods of 7-11 September 2005, J. Geophys. Res., 116, A03301, https://doi.org/10.1029/2010JA016067, 2011. 
Pawlowski, D. J., Ridley, A. J., Kim, I., and Bernstein, D. S.: Global model comparison with Millstone Hill during September 2005, J. Geophys. Res., 113, A01312, https://doi.org/10.1029/2007JA012390, 2008.

Pirog, O. M., Polekh, N. M., Tashchilin, A. V., Romanova, E. B., and Zherebtsov, G. A.: Response of ionosphere to the great geomagnetic storm of September 1998: Observation and modeling, Adv. Space Res., 37, 1081-1087, https://doi.org/10.1016/j.asr.2006.02.005, 2006.

Prölss, G. W.: Ionospheric $F$-region storms, Handbook of Atmospheric Electmdynamics, 2, edited by: Volland, H., Boca Raton, CRC Press, 195-248, 1995.

Prölss, G. W.: Ionospheric Storms at Mid-Latitude: A Short Review, Midlatitude Ionospheric Dynamics and Disturbances, edited by: Kintner, P. M., Coster, A. J., Fuller-Rowell, T., Mannucci, A. J., Mendillo, M., and Heelis, R., Geophysical Monograph Series, 181, Washington, DC, American Geophys. Union, https://doi.org/10.1029/181GM03, 2013.

Rasmussen, C. E., Guiter S. M., and Thomas S. G.: A twodimensional model of the plasmasphere: refilling time constants, Planet. Space Sci., 41, 35-43, https://doi.org/10.1016/00320633(93)90015-T, 1993.

Rishbeth, H. and Garriott, O. K.: Introduction to ionospheric physics, International Geophysics Series, New York and London: Academic Press, 14, 334 pp., 1969.

Rishbeth, H., Heelis, R. A., Makela, J. J., and Basu, S.: Storming the Bastille: the effect of electric fields on the ionospheric $F$-layer, Ann. Geophys., 28, 977-981, https://doi.org/10.5194/angeo-28977-2010, 2010.

Roble, R. G. and Ridley, E. C.: A thermosphere-ionospheremesosphere-electrodynamics general circulation model (time-GCM): Equinox solar cycle minimum simulations (30-500 km), Geophys. Res. Lett., 21, 417-420, https://doi.org/10.1029/93GL03391, 1994.

Schunk, R. W. and Nagy, A. F.: Ionospheres: physics, plasma physics, and chemistry, Cambridge atmospheric and space science series, Cambridge University Press, Cambridge, 628 pp., 2000.

Schunk, R. W. and Sojka, J. J.: Ionosphere-thermosphere space weather issues, J. Atmos. Terr. Phys., 58, 1527-1574, https://doi.org/10.1016/0021-9169(96)00029-3, 1996.

Snekvik, K., Haaland, S., Østgaard, N., Hasegawa, H., Nakamura, R., Takada, T., Juusola, L., Amm, O., Pitout, F., Rème, H., Klecker, B., and Lucek, E. A.: Cluster observations of a field aligned current at the dawn flank of a bursty bulk flow, Ann. Geophys., 25, 1405-1415, https://doi.org/10.5194/angeo-25-14052007, 2007.
Sojka, J. J., Schunk, R. W., and Denig, W. F.: Ionospheric response to the sustained high geomagnetic activity during the March'89 great storm, J. Geophys. Res., 99, 21341-21352, https://doi.org/10.1029/94JA01765, 1994.

Solomentsev, D., Jacobsen, K. S., Khattatov, B., Khattatov, V., Cherniak, Y., and Titov, A.: Ionosphere data assimilation capabilities for representing the high-latitude geomagnetic storm event in September 2011, J. Geophys. Res.-Space, 119, 1058110594, https://doi.org/10.1002/2014JA020248, 2015.

Suvorova, A. V., Dmitriev, A. V., Tsai, L.-C., Kunitsyn, V. E., Andreeva, E. S., Nesterov, I. A., and Lazutin, L. L.: TEC evidence for near-equatorial energy deposition by $30 \mathrm{keV}$ electrons in the topside ionosphere, J. Geophys. Res.-Space, 118, 4672-4695, https://doi.org/10.1002/jgra.50439, 2013.

Suvorova, A. V., Huang, C.-M., Dmitriev, A. V., Kunitsyn, V. E., Andreeva, E. S., Nesterov, I. A., Klimenko, M. V., Klimenko, V. V., and Tumanova, Y. S.: Effects of ionizing energetic electrons and plasma transport in the ionosphere during the initial phase of the December 2006 magnetic storm, J. Geophys. Res.-Space, 121, 5880-5896, https://doi.org/10.1002/2016JA022622, 2016.

Tsurutani, B. T., Mannuccei, A. J., Verkhoglyadova, O. P., and Lakhina, G. S.: Comment on "Storming the Bastille: the effect of electric fields on the ionospheric F-layer" by Rishbeth et al. (2010), Ann. Geophys., 31, 145-150, https://doi.org/10.5194/angeo-31-145-2013, 2013.

Vorobjev, V. G. and Yagodkina, O. I.: Empirical model of auroral precipitation power during substorms, J. Atm. Solar-Ter. Phys., 70, 654-662, https://doi.org/10.1016/j.jastp.2007.08.046, 2008.

Wang, C., Zhang, Q., Chi, P. J., and Li, C.: Simultaneous observations of plasmaspheric and ionospheric variations during magnetic storms in 2011: First result from Chinese Meridian Project, J. Geophys. Res.-Space, 118, 99-104, https://doi.org/10.1029/2012JA017967, 2013.

Yizengaw, E., Moldwin, M. B., Galvan, D., Iijima, B. A., Komjathy, A., and Mannucci, A. J.: Global plasmaspheric TEC and its relative contribution to GPS TEC, J. Atmosph. Solar-Terr. Phys., 70, 1541-1548, https://doi.org/10.1016/j.jastp.2008.04.022, 2008.

Zakharenkova, I. E., Cherniak, Iu. V., Krankowski, A., and Shagimuratov, I. I.: Analysis of electron content variations over Japan during solar minimum: Observations and modeling, Adv. Space Res., 52, 1827-1836, https://doi.org/10.1016/j.asr.2012.09.043, 2013. 